\title{
Pengaruh Risiko Environment Social and Governance Terhadap Kinerja Keuangan Perusahaan (Studi Pada Perusahaan Didalam Indeks IDXESGL)
}

\author{
Fahry Priandhana \\ Accounting Department, Faculty of Economics and Communication \\ Bina Nusantara University \\ Jakarta 11480, Indonesia \\ fahry.priandhana@binus.ac.id \\ *Correspondence: fahry.priandhana@binus.ac.id
}

\begin{abstract}
This study aims to analyze the effect of ESG risk on the financial performance of companies. The object of this research is companies listed on the Indonesian Stock Exchange and included in the IDXESGL index. The total sample in this study is 24 companies. The independent variable in this research is ESG risk where the data is available and generated from the Indonesian Stock Exchange cooperation with Sustainalytics. The independent variable in this study is the performance of the company represented by the ROA (Return on Asset) obtained by dividing profits by total assets. Data analysis was performed using simple linear regression and Microsoft Excel. The results of data analysis show that there is a negative effect of ESG risk on the company's financial performance. Thus, the higher the ESG risk of a company, the financial performance of the company will decrease. However, the effect of ESG risk on a company's financial performance is not significant.
\end{abstract}

Keywords: ESG risk; Financial performance; IDXESGL index.

\begin{abstract}
ABSTRAK
Penelitian ini bertujuan untuk melakukan analisis pengaruh risiko ESG terhadap kinerja keuangan perusahaan. Objek penelitian adalah perusahaan yang terdaftar di Bursa Efek Indonesia dan masuk kedalam indeks IDXESGL. Total sampel dalam penelitian ini sebanyak 24 perusahaan. Variabel independen dalam penelitian ini adalah risiko ESG yang datanya tersedia dan dihasilkan dari Kerjasama Bursa Efek Indonesia dengan Sustainalytics. Variabel independen dalam penelitian ini adalah kinerja perusahaan yang diwakili oleh ROA (Return on Asset) yang diperoleh dengan membagi laba terhadap total asset. Analisis data dilakukan dengan menggunakan regresi linear sederhana dan Microsoft Excel. Hasil analisis data menunjukkan terdapat pengaruh negatif risiko ESG terhadap kinerja keuangan perusahaan. Dengan demikian, semakin tinggi risko ESG suatu perusahaan, maka kinerja keuangan perusahaan tersebut akan turun. Akan tetapi, pengaruh risiko ESG terhadap kinerja keuangan perusahaan tidak signifikan.
\end{abstract}

Kata kunci: Risiko ESG; Kinerja Keuangan; Indeks IDXESGL. 


\section{PENDAHULUAN}

Meningkatnya kesadaran masyarakat dunia terhadap isu-isu lingkungan, memiliki dampak yang luas ke berbagai bidang kehidupan, tidak terkecuali bidang akuntansi dan finansial. Dalam praktek akuntansi, Birt (2019) menyatakan bahwa UNDSD (United Nations Division for Sustainable Development) telah mengeluarkan guidelines mengenai environmental management accounting procedures and principles untuk membantu para praktisi manajemen akuntan dalam menghadapi informasi yang sangat ekstensif mengenai data lingkungan di suatu organisasi. Informasi mengenai lingkungan harus dapat disajikan agar para pemangku kepentingan (stakeholders) dapat memahami kondisi non-finansial dari suatu perusahaan.

Pada praktek konvensional, laba dan indikator finansial lainnya, menjadi hal yang paling utama, meskipun saat ini penilaian kinerja suatu perusahaan tidak lagi semata-mata hanya mengandalkan indikator finansial. Datar (2018) menyatakan bahwa penilaian kinerja perusahaan yang menggunakan balance scorecard sudah berkembang dengan memasukkan penilaian atas kinerja lingkungan dan sosial. Lebih jauh lagi, Datar (2018) juga menyatakan bahwa kegagalan suatu perusahaan untuk secara memadai menghasilkan kinerja yang baik dalam menjaga lingkungan dan bidang sosial dapat menyebabkan perusahaan berisiko tinggi dalam memberikan nilai masa depan kepada para pemegang sahamnya.

Penilaian kinerja perusahaan terhadap Environment Social dan Governance (ESG) sudah dilakukan oleh lembaga-lembaga pemeringkat di dunia, seperti Standard \& Poor's, Bloomberg dan Fitch. Bursa-bursa saham di seluruh dunia juga memiliki indeks saham untuk emiten yang dinilai memiliki praktek ESG yang baik, seperti bursa saham amerika (NYSE), bursa saham Singapura (SGX) dan termasuk juga bursa saham Indonesia (IDX). Indeks kinerja ESG yang dibuat oleh bursa saham Indonesia adalah IDXESGL. Dalam penelitian ini, data risiko ESG yang dipakai, menggunakan data dari indeks IDXESGL yang merupakan data risiko ESG yang dikeluarkan oleh Sustainalytics yang bekerja sama dengan Bursa Efek Indonesia. Berdasarkan panduan indeks IDX ESG Leaders (November 2020) Sustainalytics merupakan lembaga penilai risiko ESG yang dipercaya oleh Bursa Efek Indonesia untuk memberikan nilai risiko ESG atas emiten yang tercatat di Bursa Efek Indonesia.

Penelitian yang dilakukan oleh Sciareli (2019) menyatakan bahwa ESG ratings memiliki dampak positif kepada kinerja keuangan perusahaan. Almeyda (2019) menghasilkan penelitian yang menyatakan bahwa pengungkapan ESG memiliki pengaruh positif yang signifikan terhadap kinerja keuangan perusahaan yaitu ROA (Return on Asset) dan ROC (Return on Capital). Penelitian ini dilakukan dengan menggunakan pendekatan risiko ESG dan pengaruhnya terhadap kinerja keuangan perusahaan berupa ROA. Tujuan dari penelitian ini adalah untuk mengetahui apakah risiko ESG mempengaruhi kinerja keuangan perusahaan.

\section{METODE PENELITIAN}

Objek dalam penelitian ini adalah perusahaan-perusahaan yang masuk kedalam indeks IDXESGL pada periode Mei 2021 sampai September 2021. Selama periode tersebut, Bursa Efek Indonesia memperbaharui emiten yang masuk kedalam indeks IDXESGL sebanyak dua kali. Jumlah emiten yang masuk kedalam indeks IDXESGL adalah sebanyak 30 perusahaan. Akan tetapi, karena selama periode penelitian ini terdapat satu perusahaan yang keluar dan diganti oleh otoritas Bursa Efek Indonesia, maka objek penelitian ini dikurangi menjadi 29 perusahaan yang masuk kedalam indeks ESGL selama dua kali berturut-turut. Untuk menghilangkan bias data, kinerja perusahaan yang bernilai negatif juga dikeluarkan dari objek penelitian, sehingga total jumlah perusahaan yang menjadi objek penelitian ini adalah 24 perusahaan.

Variabel independen dalam penelitian ini adalah risiko ESG yang dikeluarkan oleh Sustainalytics. Nilai risiko ESG yang rendah menggambarkan bahwa perusahaan memiliki risiko ESG yang rendah, karena perusahaan dapat menerapkan ESG dengan baik. Sebaliknya, nilai risiko ESG yang tinggi, menggambarkan perusahaan kurang baik dalam menerapkan ESG, sehingga memiliki risiko ESG yang tinggi.

Kinerja perusahaan yang menjadi variabel independen dalam penelitian ini, diwakili oleh nilai ROA (Return on Asset) yang dihitung dengan cara membagi laba setiap periode dengan nilai asset selama periode tersebut. Bursa Efek Indonesia memperbaharui IDXESGL pada periode Maret 2012 dan Juni 2021, sehingga data ROA yang digunakan adalah data ROA pada kuartal pertama tahun 2021. 
Analisis data dalam penelitian ini menggunakan regresi linear sederhana dengan bantuan software Microsoft Excel. Menurut Garisson (2015), fitur rumus (formula) dalam Microsoft Excel dapat digunakan untuk melakukan analisis regresi dengan menerapkan rumus INTERCEPT, SLOPE dan RSQ. Dalam persamaan regresi linear sederhana, hubungan antara variabel independen $(\mathrm{X})$ dan variabel dependen $(\mathrm{Y})$ digambarkan sebagai $\mathrm{Y}=(\mathrm{a})+$ (b)X, dimana rumus pada Microsoft Excel INTERCEPT digunakan untuk mencari besaran nilai (a) dan rumus SLOPE digunakan untuk mencari besaran nilai (b). Sedangkan rumus RSQ, digunakan untuk mencari besaran nilai R kuadrat (R Square) yang dalam ilmu statistika digunakan untuk menggambarkan seberapa besar pengaruh variabel independen terhadap variabel dependennya.

\section{HASIL DAN PEMBAHASAN}

Olah data pada penelitian ini dilakukan dengan mengumpulkan informasi mengenai nilai risko ESG dan nilai ROA dari 24 perusahaan yang terdaftar di Bursa Efek Indonesia. Data nilai risiko ESG dan laporan keuangan perusahaan tersebut, merupakan data publik yang dapat diakses melalui website Bursa Efek Indonesia. Berikut adalah table rangkuman data risiko ESG dan ROA.

Table 1 Data Risiko ESG dan ROA

\begin{tabular}{|c|c|c|c|}
\hline No & Kode Perusahaan & Risiko ESG & ROA \\
\hline 1 & ACES & 18,42 & 2,175 \\
\hline 2 & AKRA & 27,44 & 2,053 \\
\hline 3 & ASII & 28,42 & 1,956 \\
\hline 4 & BBCA & 26,08 & 0,438 \\
\hline 5 & BBNI & 27,51 & 0,251 \\
\hline 6 & BBRI & 25,34 & 0,336 \\
\hline 7 & BMRI & 29,71 & 0,194 \\
\hline 8 & BSDE & 22,76 & 0,683 \\
\hline 9 & BULL & 24,73 & 1,334 \\
\hline 10 & CTRA & 27,03 & 0,832 \\
\hline 11 & DMAS & 26,31 & 4,102 \\
\hline 12 & ERAA & 11,77 & 2,682 \\
\hline 13 & EXCL & 25,65 & 0,525 \\
\hline 14 & HMSP & 25,73 & 5,634 \\
\hline 15 & INTP & 27,22 & 1,286 \\
\hline 16 & MAPI & 20,50 & 0,255 \\
\hline 17 & $\mathrm{MNCN}$ & 18,49 & 2,081 \\
\hline 18 & PWON & 26,92 & 0,954 \\
\hline 19 & SCMA & 19,73 & 5,087 \\
\hline 20 & TBIG & 27,71 & 1,382 \\
\hline 21 & TLKM & 26,76 & 3,288 \\
\hline 22 & TOWR & 27,65 & 2,132 \\
\hline 23 & UNVR & 18,48 & 7,499 \\
\hline 24 & WOOD & 13,21 & 1,686 \\
\hline
\end{tabular}

Pada Table 1 diatas, data risiko ESG merupakan penilaian dari Sustainalytics yang sudah tersedia dalam website Bursa Efek Indonesia. Data ROA pada Table 1 diatas, diperoleh dari laporan keuangan masing-masing perusahaan dan dihitung dengan cara membagi nilai laba dengan total asset.

Secara teoritis, ketika risiko ESG tinggi, maka kinerja perusahaan akan turun, sehingga hubungan antara risiko ESG dengan kinerja perusahaan adalah negatif. Ketika analisis data risiko ESG dan kinerja perusahaan dimasukkan kedaam Microsoft Excel dengan menggunakan rumus SLOPE, diperoleh hasil negatif yaitu -0,115. 
Hasil negatif ini, menunjukkan bahwa hubungan antara risiko ESG dengan kinerja perusahaan adalah negatif, sehingga semakin tinggi risiko ESG, maka semakin kecil kinerja perusahaan.

Persamaan regresi linear dapat digambarkan dengan rumus $\mathrm{Y}=(\mathrm{a})+(\mathrm{b}) \mathrm{X}$. Untuk memperoleh besaran nilai (a) digunakan rumus INTERCEPT dalam Microsoft Excel dan mendapatkan hasil sebesar 4,79. Sedangkan nilai (b) pada persamaan regresi sudah diperoleh dengan menggunakan rumus SLOPE sebelumnya, yaitu negatif $-0,115$. Dengan demikian persamaan regresi sederhana yang dihasilkan dari analisis pengaruh risiko ESG terhadap kinerja keuangan perusahaan adalah $\mathrm{Y}=47,9-0,115 \mathrm{X}$.

\section{Diskusi}

Untuk menggambarkan besarnya pengaruh risiko ESG dengan kinerja keuangan perusahaan, digunakan rumus RSQ dalam Microsoft Excel dan menghasilkan nilai R square sebesar 9\%. Hasil R square sebesar 9\%, artinya faktor risiko ESG dapat mempengaruhi kinerja perusahaan sebesar 9\% dan sisanya karena faktor-faktor lain. Dengan besaran pengaruh yang hanya 9\% maka dapat dikatakan risiko ESG masih memiliki pengaruh terhadap kinerja perusahaan, tetapi pengaruh tersebut tidak terlalu signifikan. Masih terdapat banyak faktor-faktor lain yang mempengaruhi kinerja keuangan perusahaan.

Kondisi pandemi Covid-19, kemungkinan besar memiliki peran dalam mempengaruhi kinerja keuangan perusahaan, karena menurut Noor (2015), dalam kondisi financial crisis, faktor kinerja lingkungan (environment performance) tidak memiliki pengaruh yang signifikan terhadap kinerja keuangan perusahaan. Sehingga terdapat kemungkinan walaupun perusahaan memiliki risiko ESG yang rendah, hal tersebut tidak terlalu berpengaruh ketika masa pandemi Covid-19 yang menyebabkan krisis keuangan di berbagai perusahaan.

\section{KESIMPULAN}

Hasil pengujian variabel risiko ESG dan kinerja keuangan perusahaan dengan menggunakan regresi sederhana, dalam melakukan analisis pengaruh risko ESG terhadap kinerja keuangan, menunjukkan bahwa terdapat pengaruh yang bersifat negatif. Dengan demikian, dapat disimpulkan bahwa semakin tinggi risiko ESG suatu perusahaan, maka kinerja keuangan akan menurun. Sebaliknya, ketika risiko ESG rendah, maka kinerja keuangan perusahaan akan naik.

Pengaruh terhadap kinerja keuangan yang diakibatkan oleh faktor risiko ESG tidak terlalu signifikan, karena hasil dari R square menunjukkan nilai 9\% yang artinya risiko ESG ini hanya berperan sebesar 9\% saja dalam mempengaruhi kinerja keuangan, selebihnya adalah karena faktor-faktor lain. Untuk mendapatkan hasil yang lebih baik, disarankan agar penelitian selanjutnya menggunakan basis data yang lebih luas dan bebas bias dari efek pandemi Covid-19 yang menyebabkan krisis keuangan perusahaan. Selain itu penelitian selanjutnya juga disarankan untuk menggunakan variabel yang lebih banyak, terutama variabel yang terkait dengan Environment, Social and Governance. 


\section{DAFTAR PUSTAKA}

Almeyda, Raisa., Darmansyah, Asep. (2019). The Influence of Environmental, Social and Governace (ESG) Disclosure on Firm Financial Performance. IPTEK Journal of Proceedings Series No (5)

Birt, J., K. Chalmers, S. Maloney, A. Brooks, \& J. Oliver. (2019). Accounting Business Reporting for Decision Making. 7. Australia: John Wiley \& Son.

Bursa Efek Indonesia. (November 2020). Panduan Indeks ESG Leaders Versi 1.1. Jakarta: Bursa Efek Indonesia

Datar, Srikant M., Rajan, Madhav V. (2018). Horngren's Cost Accounting: A Managerial Emphasis 16. Global Edition: Pearson. Harlow.

Garrison, Ray H., Noreen, Eric., Brewer, Peter., Seng, C Nam., Yuen Katherine. (2015). Managerial Accounting An Asian Perspective. 2. Singapore: McGraw-Hill.

Noor, Muhammad., Scrimgeur, Frank., Reddy, Krishna., Abidin, Sazali. (2015). The Relationship Between Environmental Performance and Financial Performance in Periods of Growth and Contraction: Evidence from Australian Publicly Listed Companies. Journal of Cleaner Production Volume 102, Pages 324332.

Sciarelli, Mauro., Landi, Giovanni. (2018). Towards a More Ethical Market: The Impact of ESG Rating on Corporate Financial Performance. Social Responsibility Journal ISSN: 1747-1117 